\title{
The Pharmacokinetics of Inhaled Morphine Delivered by an Ultrasonic Nebulizer in Ventilated Dogs
}

\author{
Xin Xu, M.D., ${ }^{1}$ Xiaohai Wang, M.D.,' Weihong Ge, M.D., ${ }^{2}$ Lin Pan, Post Graduate, ${ }^{3}$ and Man Zheng, M.D. ${ }^{1}$
}

\begin{abstract}
Background: To investigate the pharmacokinetics of single dose morphine inhaled by modified ultrasonic nebulizer versus intravenous administered in ventilated dogs.

Methods: Six healthy dogs were randomly assigned to receive nebulized or intravenous morphine and crossed over to the alternative medication 1 week after. Morphine was nebulized by modified ultrasonic nebulizer (YuYue 402A, Jiangsu, China). Arterial blood was sampled every minute during the $10 \mathrm{~min}$ of administration and at 2, 5, 7, 10, 15, 20,45, 60, 90, 120, 150, 180, 240, and $360 \mathrm{~min}$ after the administration for the determination of morphine concentration by RP-HPLC.

Results: The main pharmacokinetic parameters of morphine by inhaled and intravenous administration were: MRT $59 \pm 14 \mathrm{~min}$ versus $19 \pm 4 \mathrm{~min}, T_{1 / 2} 21.9 \pm 5.1 \mathrm{~min}$ versus $3.3 \pm 1.0 \mathrm{~min}, T_{\max } 23.0 \pm 2.7 \mathrm{~min}$ versus $8.8 \pm 2.4 \mathrm{~min}$, $C_{\max } 0.245 \pm 0.09 \mathrm{mg} \cdot \mathrm{L}^{-1}$ versus $1.09 \pm 0.32 \mathrm{mg} \cdot \mathrm{L}^{-1}, \mathrm{AUC}_{0-\infty} 9.7 \pm 1.1 \mathrm{mg} \cdot \mathrm{min} \cdot \mathrm{L}^{-1}$ versus $15.2 \pm 7.2 \mathrm{mg} \cdot \mathrm{min} \cdot \mathrm{L}^{-1}$, CL $0.069 \pm 0.019 \mathrm{~L} \cdot \mathrm{min}^{-1} \cdot \mathrm{kg}^{-1}$ versus $0.063 \pm 0.028 \mathrm{~L} \cdot \mathrm{min}^{-1} \cdot \mathrm{kg}^{-1}$, and the absolute bioavailability of inhaled morphine was $35.5 \pm 10 \%$. There were no significant differences $(p<0.05)$ between inhaled and intravenous morphine in AUC and CL. As expected, the $T_{1 / 2}$ and MRT of inhaled morphine were significantly greater than those of intravenous morphine.

Conclusions: Morphine nebulized by ultrasonic nebulizer can be rapidly and extensively absorbed by lungs in ventilated dogs.
\end{abstract}

Key words: morphine, inhaled, ultrasonic, nebulized, pharmacokinetic, mechanical ventilation

\section{Introduction}

A S ONE OF THE MOST POPULAR Opioid analgesics, morphine was usually administered by conventional routes, such as orally, intramuscularly, intravenously, and subcutaneously. Recently, pulmonary delivery system has been regarded as a potential route of opioid administration on the basis of the fact that small molecular entities can be rapidly and highly absorbed from the alveoli membrane because their large surface area and high permeability. It was reported that the pulmonary delivery of morphine as a pain therapeutic method was simple, rapid, noninvasive, safe, and effective. ${ }^{(1-5)}$ Based on the results of the pharmacokinetics of inhaled morphine, we can find that although it had a lower bio- availability than the AERx pulmonary delivery system, the ultrasonic nebulizer was efficient at least equivalent to the jet nebulizer in delivering aerosol drug to lungs. ${ }^{(6-11)}$ However, both jet nebulizer and AERx pulmonary delivery system were open systems, which were unable to deliver morphine to the pulmonary system during mechanical ventilation, although some studies about it had aroused clinical attention. ${ }^{(12-14)}$ To apply the technique of nebulization during mechanical ventilation, we modified the ultrasonic nebulizer and had it converted to a closed configuration so that it could be connected to the ventilator. ${ }^{(15)}$ In this random crossover study, we investigated the pharmacokinetics of morphine inhaled versus intravenous administration in ventilated dogs with this modified ultrasonic nebulizer.

Anesthesiology Department, Nanjing Drum Tower Hospital, the Affiliated Hospital of Nanjing University Medical School, Nanjing, People's Republic of China 210008.

${ }^{2}$ Pharmacy Department, Nanjing Drum Tower Hospital, the Affiliated Hospital of Nanjing University Medical School, Nanjing, People's Republic of China 210008.

${ }^{3}$ Nanjing University Medical School, Nanjing, People's Republic of China 210008. 


\section{Materials and Methods}

\section{Modification of an ultrasonic nebulizer}

The original ultrasonic nebulizer (YuYue 402A, Jiangsu, China) (Fig. 1) was an open system designed for patients with spontaneous inspiration. We had the ultrasonic nebulizer modified in three steps. First, cancel the original inlet and rebuild the connection of the upper part and lower part of nebulization chamber into a screw to contain the whole system. Second, modify the two gas vents to the middle top of the nebulization chamber, one as a fresh air entrance to the ventilator and the other as a mixed air exit to the therapeutic subjects. Third, separate the upper nebulization chamber along anteroposterior axes to isolate fresh air and mixed air. As a result, when fresh air came into the upper nebulization chamber, it would go to the lower part and carry the aerosol nebulized by the nebulizing film at the bottom to the other part of the upper nebulization chamber and then exit to the therapeutic subjects (Fig. 2).

\section{Subject selection and grouping}

The study protocol was approved by the institutional ethics committee boards of our hospital. Six healthy dogs (three female, three male, age $2-3$ years, weight $10.1 \pm 1.7 \mathrm{~kg}$ ) were recruited and randomly assigned to receive either a single dose of $1.32 \mathrm{mg} / \mathrm{kg}$ morphine within $10 \mathrm{~min}$ by pulmonary delivery using the modified ultrasonic nebulizer (the inhalation group) or a single dose of $0.66 \mathrm{mg} / \mathrm{kg}$ by intravenous administration using the microinfusion pump (the intravenous group) during mechanical ventilation. After a 1- week washout period, a crossover medication was made by the alternative administration to each dog.

The dose was doubled in the inhalation group because in our previous study we found that there was always $3 \mathrm{~mL}$ residual after the $10 \mathrm{~min}$ of nebulization, and in this study morphine was diluted into $6 \mathrm{~mL}$ to load to the nebulizer.

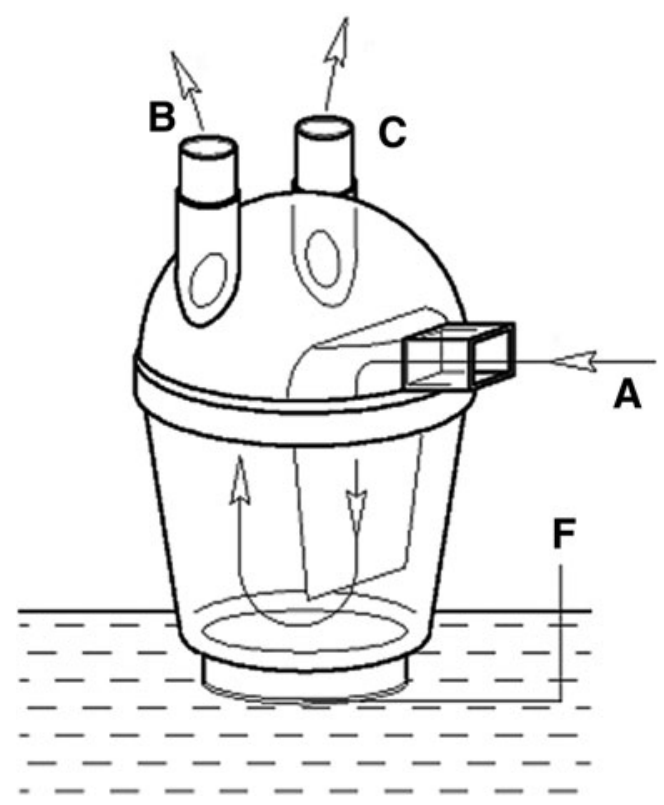

FIG. 1. The original nebulization cup (A, inlet; B, C, air vent; F, nebulizing film).

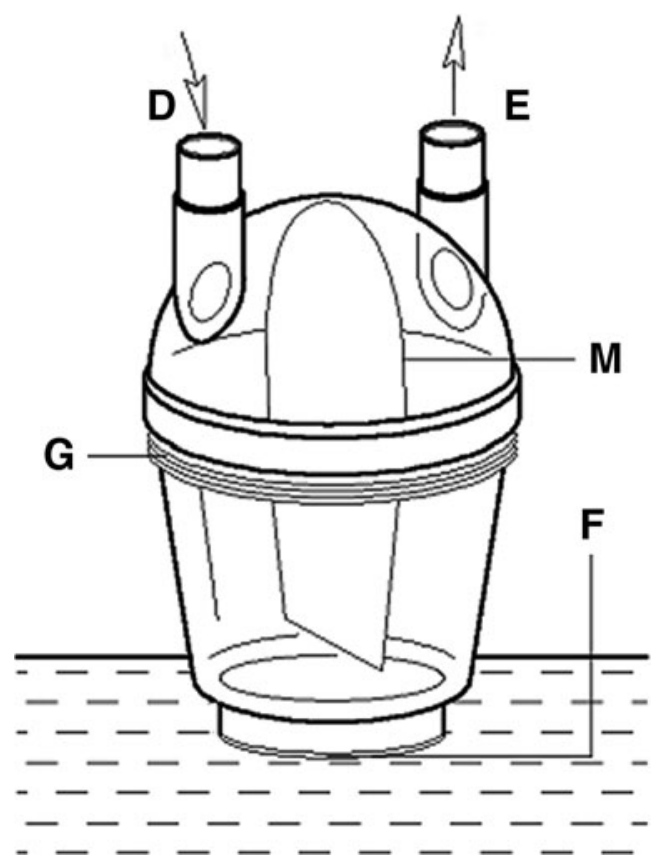

FIG. 2. The reformed nebulization cup (D, fresh air entrance; $E$, mixed air exit; F, nebulizing film; G, screw; $M$, intermediate partition).

\section{Anesthesia and administration}

After fasting $12 \mathrm{~h}$, the subjects were anesthetized with 10 $15 \mathrm{mg} \cdot \mathrm{kg}^{-1}$ of ketamine, $0.5 \mathrm{mg}$ of atropine, and $10 \mathrm{mg}$ of droperidol intramuscularly, and intravenous transfusion was then started at a rate of $200-250 \mathrm{~mL} / \mathrm{h}$ from left forearm vein. Mechanical ventilation was applied after tracheal intubation (Drager Ventilator, Savina, Germany). The ventilation parameters were set as follows: tidal volume $13-15 \mathrm{~mL} \cdot \mathrm{kg}^{-1}$, respiratory rate $18 \cdot \mathrm{min}^{-1}$ with an inspiratory time $1.1 \mathrm{sec}$, $29 \% \mathrm{FiO}_{2}$ at a flow rate of $2 \mathrm{~L} \cdot \mathrm{min}^{-1}$. The anesthesia was maintained with intravenous administration of propofol at 200-300 $\mu \mathrm{g} \cdot \mathrm{kg}^{-1} \cdot \mathrm{min}^{-1}$ and intermittent i.v. of ketamine $\tilde{3} 4 \mathrm{mg} \cdot \mathrm{kg}^{-1}$ when needed. The right femoral artery was cannulated with a 20-gauge catheter connected to a threeway stopcock for serial blood sampling and blood pressure monitoring. Half an hour after the induction of anesthesia, when arterial blood pressure got steady, all subjects in the intravenous group received a single dose of $0.66 \mathrm{mg} / \mathrm{kg}$ morphine (morphine solution diluted to $6 \mathrm{~mL}$ with $0.9 \%$ $\mathrm{NaCl}$ solution) administered by microinfusion pump (Graseby 3100 pump) within $10 \mathrm{~min}$, while a single dose of $1.32 \mathrm{mg} / \mathrm{kg}$ in $6 \mathrm{~mL}$ was loaded to the ultrasonic nebulizer to deliver intratracheally in the inhalation group instead.

Meanwhile, one simulation test was carried out where one group of 10 samples of morphine solution was nebulized under the same condition as in the inhalation group, and the morphine concentration was detected before and after the $10 \mathrm{~min}$ of nebulization to determine the real dose that nebulized and delivered.

\section{Samples collection and HPLC analysis}

Arterial blood of $1 \mathrm{~mL}$ was sampled every minute during the $10 \mathrm{~min}$ of administration of morphine, and at 2, 5, 7, 10, 
$15,20,45,60,90,120,150,180,240$, and $360 \mathrm{~min}$ after the administration in heparined tubes. All blood samples were centrifugated at $3500 \mathrm{rpm}^{-1}$ for $10 \mathrm{~min}$ to get plasma, which were then stored at $-20^{\circ} \mathrm{C}$ until analysis.

The plasma samples of $100 \mu \mathrm{L}$ were first mixed well with $5 \mu \mathrm{L}$ of internal standard solution (ferulic acid $2 \mathrm{mg} / \mathrm{L}$ in methanol), then $100 \mu \mathrm{L}$ of $50 \mathrm{mmol} / \mathrm{L}$ phosphate buffer and $700 \mu \mathrm{L}$ of ethyl acetate (EtOAc) were added. After vortexmixing and centrifugation, the supernatant was dried under nitrogen evaporation at $40^{\circ} \mathrm{C}$. The residue was dissolved in HPLC mobile phase, of which $20 \mu \mathrm{L}$ was analyzed by reverse-phase high performance liquid chromatography (RPHPLC). The RP-HPLC system consisted of an Agilent 1100 binary pump system equipped with a G1314 UV-detector. The HPLC mobile phase was $0.2 \%$ triethylamine solution $(\mathrm{pH}$ 6.89), methanol $(78: 22, \mathrm{v} / \mathrm{v})$ with the velocity of $1.0 \mathrm{~mL} \cdot \mathrm{min}^{-1}$. Chromatographic separation was achieved on a Kromasil C18 column ( $150 \mathrm{~mm} \times 4.6 \mathrm{~mm}, 5 \mu \mathrm{m})$ (Hanbang, Jiangsu) with the detection wavelength at $215 \mathrm{~nm}$. A complete separation was obtained under these chromatographic condition with retention times for morphine and internal standard of $11.890 \mathrm{~min}$ and $3.67 \mathrm{~min}$ (Fig. 3).

The standard curves were prepared by plotting peak area ratios of morphine against the morphine concentration and
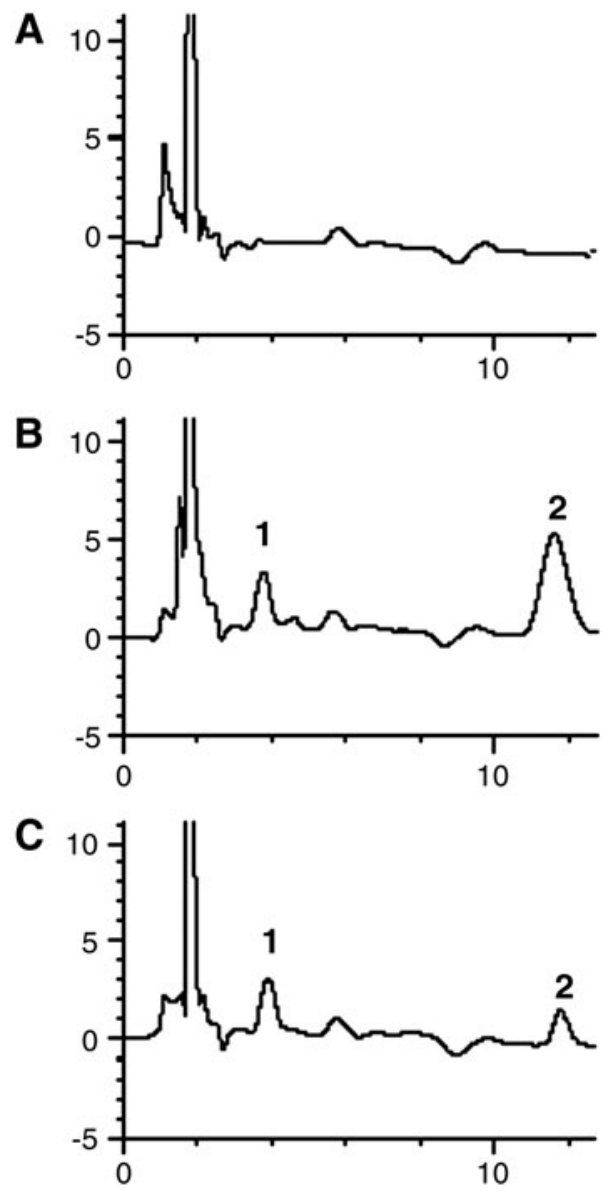

FIG. 3. Chromatogram. (A) Blank plasma; (B) standard preparation; (C) sample plasma. (1: internal standared paracetamol, retention time $3.487 \mathrm{~min}$; 2: morphine, retention time $11.890 \mathrm{~min})$. analyzed by the linear least-squares regression analysis. The standard curve for morphine was linear over the concentration range of $5-2000 \mathrm{ng} / \mathrm{mL} \quad(\mathrm{y}=1.4368 \mathrm{x}+0.0201$, $\left.r^{2}=0.9994\right)$. For the validation of the HPLC method, precision and accuracy were determined by repeated analysis of three concentration levels of quality control samples $(25,100$, and $1000 \mathrm{ng} \cdot \mathrm{mL}^{-1}, n=5$ ) on 5 separate days. The minimum detectable concentration was $2 \mathrm{ng} \cdot \mathrm{mL}^{-1}(\mathrm{~S} / \mathrm{N}$ ratio, $3: 1)$. The recoveries of internal standard were $84.29 \%$ to $106.45 \%$. The innerday and interday precisions (as the percentage relative standard deviation) ranged from 5.98 to $8.86 \%$ and 7.82 to $11.40 \%$, respectively.

\section{Statistics}

All data were presented as mean \pm standard deviation, and all statistical tests were two sided with significance level of 0.05 . The pharmacokinetic parameters of morphine were got from Drug and Statistics Ver1.0, including the area under the concentration-time curve extrapolated to infinity $\left(\mathrm{AUC}_{(0-\infty)}\right)$, peak plasma concentration $\left(C_{\max }\right)$, the time to reach $C_{\max }\left(T_{\max }\right)$, and the mean residence time (MRT $(0-t)$ ). Meanwhile, the terminal half-life $\left(T_{1 / 2}\right)$ and the clearance rate (CL) were obtained according to compartment model analysis. The absolute bioavailability was calculated by $\mathrm{F}=(\mathrm{AUC}$ inhalation $\times$ Dose i.v.) $/($ AUC i.v. $\times$ dose inhalation $) \times 100 \%$, where the dose inhalation is the nebulizer loaded dose of $1.32 \mathrm{mg} / \mathrm{kg}$. SPSS for Windows statistical package was used. Correlations were determined with simple linear regression models. Values of pharmacokinetic parameters for the inhaled and intravenous morphine were compared by paired Student's $t$ - test.

\section{Results}

There was a rapid appearance of morphine in arterial blood after pulmonary administration, and the plasma concentration of morphine peaked about $23 \mathrm{~min}$ after the administration. The variation of plasma morphine concentrations at the selected time in two groups is presented in Table 1. The curve of morphine plasma concentration-time is displayed in Figure 4. There were no significant differences $(p<0.05)$ on AUC and CL between these two groups. However, $T_{1 / 2}$ was significantly longer in the inhalation group than that in the intravenous group $(21.9 \pm 5.1 \mathrm{~min}$ vs. $3.3 \pm 1.0 \mathrm{~min}, p=0.003$ ), and MRT in the inhalation group was also significantly prolonged compared with the intravenous group $(59 \pm 14 \mathrm{~min}$ vs. $19 \pm 4 \mathrm{~min}, p=0.019)$. $T_{\max }$ of the inhalation group was significant longer than that of the intravenous group $(23.0 \pm 2.7 \mathrm{~min}$ vs. $8.8 \pm 2.4 \mathrm{~min}$ from the beginning of administration, $p=0.03)$. $C_{\max }$ of the inhalation group decreased significantly compared with that of the intravenous group. The absolute bioavailability of inhaled morphine was $(35.5 \pm 10) \%$ (Table 2$)$.

The simulate test showed that there was no significant change on morphine concentration before and after the 10 min of nebulization (Table 3 ).

\section{Discussion}

Recently, close attention has beens paid to the pulmonary delivery systems, including the air-jet nebulizer, ultrasonic nebulizer, and the unit-dose inhaler of the AERx pulmonary 
Table 1. Variation of Plasma Morphine Concentrations at Selected Times in Two Groups (ng/mL, Mean \pm SD)

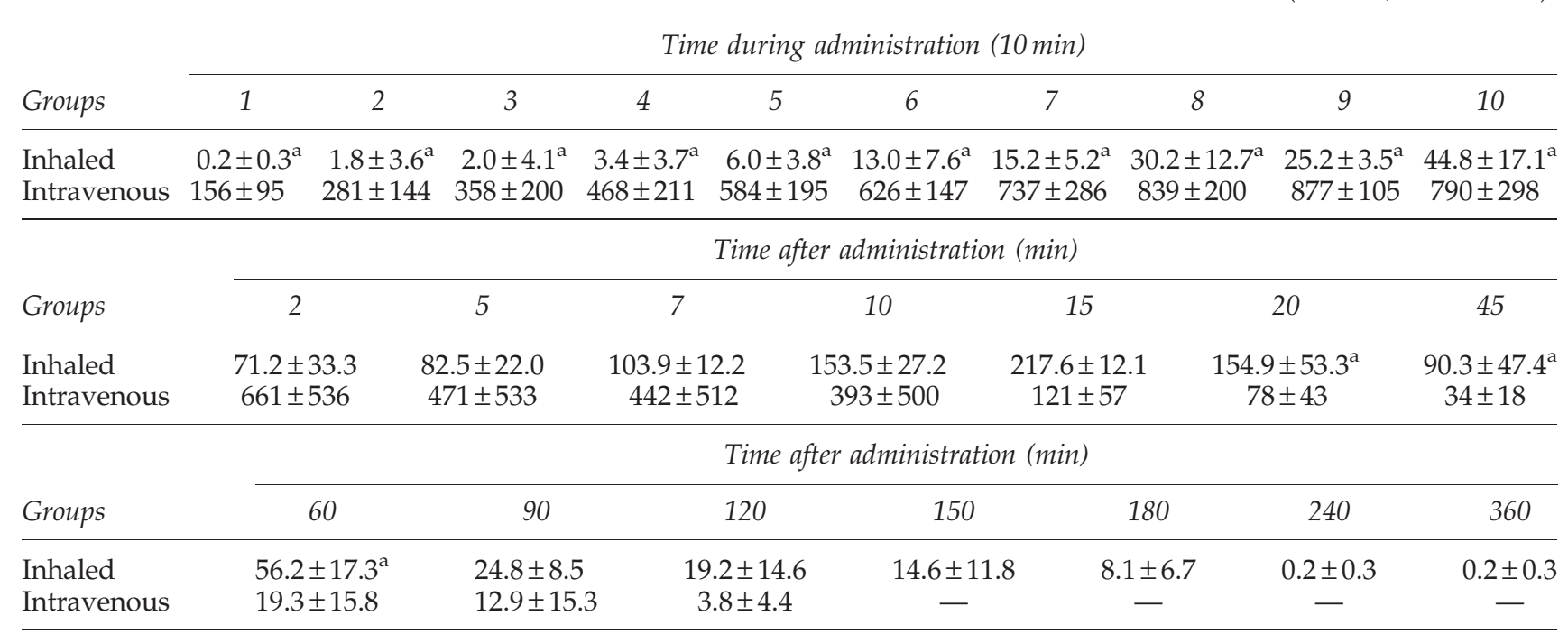

${ }^{a} p<0.05$ means the difference between two groups was significant at the time.

delivery system. The air-jet nebulizer has been applied successfully for the pulmonary administration of morphine in clinic. But all of them are open systems, which usually are well suited for the patients with spontaneous breath, while unable to be applied during mechanical ventilation. As a result, there is lack of the pharmacokinetics data on inhaled morphine using ultrasonic nebulizer under mechanical ventilation. We modified the ultrasonic nebulizer and had it connected closely to the ventilator for the pulmonary administration of morphine during general anesthesia and mechanical ventilation. The previous simulate experiments showed that the ventilator could work normally when it was connected with the modified ultrasonic nebulizer. ${ }^{(15)}$ The present study confirmed that the modified ultrasonic nebulizer and ventilator were all doing well.

The pharmacokinetic data showed that morphine could be detected quickly in arterial blood after pulmonary delivered by the modified ultrasonic nebulizer. The results of longer $T_{\max }$ and lower $C_{\max }$ in the inhalation group than those in the intravenous group indicate that the administration of

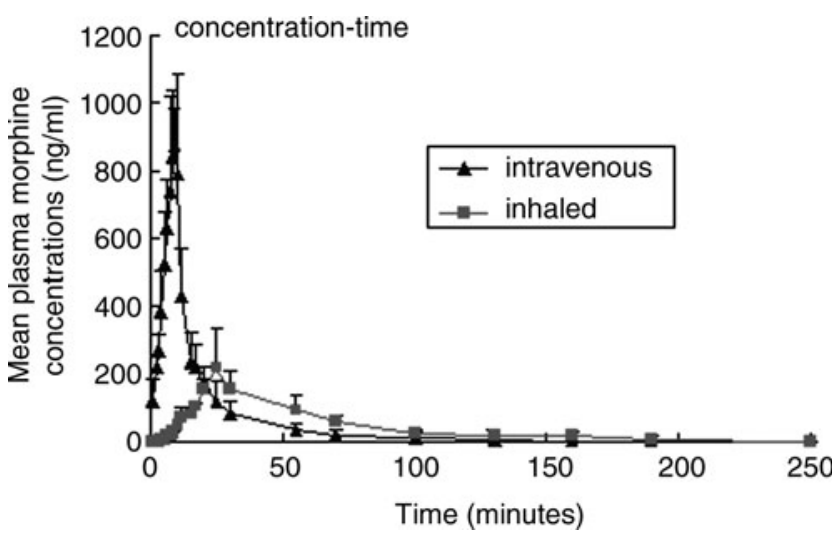

FIG. 4. Plasma morphine concentrations by intravenous and inhaled administration in six dogs in the randomized crossover study. morphine via intratracheal tube could produce a longer duration of action. In our previous study, we also found the inhalation of morphine nebulized by this modified ultrasonic atomizer via an intratracheal tube before the end of operation could produce longer and satisfying postoperative pain relieving in obstetric and gynecologic patients. Obviously the pharmacokinetic results of $T_{\max }$ and lower $C_{\max }$ in the inhalation animal is in conformity with the pharmacodynamics feature in the clinic. ${ }^{(16)}$ We think that the longer and satisfying analgesic effect in postoperative patients is based on the slowly absorption of morphine from lungs. It is well known that the inhaled morphine must travel through the pneumocytes and the vessel walls into blood circulation, while intravenous morphine was directly infused into circulatory system. As a result, the $T_{1 / 2}$ and the MRT of inhaled morphine were significantly prolonged than those of intravenous morphine. Compared with intravenous morphine, the curve of blood morphine concentration-time showed that plasma morphine concentrations from $10 \mathrm{~min}$ to $60 \mathrm{~min}$ after the administration of inhaled morphine were significantly higher. These data suggested that nebulized morphine has a better pharmacokinetics profile in slow release and lower toxicity than the intravenous morphine.

The absolute bioavailability of inhaled morphine in this study was $(30.5 \pm 10) \%$, which was lower than the $59 \%$ reported in Dershwitz's ${ }^{(9)}$ study using the AER $\times$ system and higher than the $17 \%$ reported in Chrubasik's study ${ }^{(6)}$ using the jet nebulizer. In fact, in our study there was always $3 \mathrm{~mL}$ residual fluid in the nebulizer, so the real dose delivered to the dog was only $3 \mathrm{~mL}$ of the $6 \mathrm{~mL}$ loaded to the nebulizer. Meanwhile, as shown in Table 3, morphine concentration in the residual remained unchanged; thus, the real nebulized and delivered dose should be $0.66 \mathrm{mg} / \mathrm{kg}$ in stead of $1.32 \mathrm{mg} / \mathrm{mg}$, and the absolute bioavailability might get doubled accordingly. Therefore, it suggests that morphine could have a high bioavailability when it is nebulized by the ultrasonic nebulizer during mechanical ventilation.

The bioavailability of inhaled drug is closely related to the aerosol efficiency of drugs. The mechanism of the ultrasonic 
Table 2. Main Pharmacokinetic Parameters of Morphine in Both Groups

\begin{tabular}{lcccccc}
\hline Group & $\mathrm{T}_{\max }(\min )$ & $\mathrm{C}_{\text {max }}\left(\mathrm{mg}^{-1}\right)$ & $A U C_{0-\infty}\left(\mathrm{mg} \cdot \mathrm{mL} \cdot \mathrm{min}^{-1}\right)$ & $\mathrm{T}_{1 / 2}(\mathrm{~min})$ & $\mathrm{MRT}_{(0-\mathrm{t})}(\mathrm{min})$ & $\mathrm{CL}\left(\mathrm{L} \cdot \mathrm{min}^{-1} \cdot \mathrm{kg}^{-1}\right)$ \\
\hline Inhaled & $23.0 \pm 2.7$ & $0.245 \pm 0.09$ & $9.7 \pm 1.1$ & $21.9 \pm 5.1$ & $59 \pm 14$ & $0.069 \pm 0.019$ \\
Intravenous & $8.8 \pm 2.4$ & $1.09 \pm 0.32$ & $15.2 \pm 7.2$ & $3.3 \pm 1.0$ & $19 \pm 4$ & $0.063 \pm 0.028$ \\
$p$-value & 0.03 & 0.005 & 0.4 & 0.003 & 0.019 & 0.933 \\
\hline
\end{tabular}

$C_{\max }$, peak plasma concentration; $T_{\max }$, time to reach $C_{\max }, \mathrm{AUC}_{0-\infty}$, area under the blood morphine concentration-time curve extrapolated to infinity; $T_{1 / 2}$, terminal half-life; $\mathrm{MRT}_{(0-t)}$, mean residence time; $\mathrm{CL}$, clearance rate.

Table 3. Morphine Concentration Before and After the 10-Min Nebulization (Ng/mL, Mean \pm SD)

\begin{tabular}{|c|c|c|c|c|c|c|c|c|c|c|c|c|c|}
\hline & \multicolumn{10}{|c|}{ Sample number } & \multirow[b]{2}{*}{ Mean } & \multirow{2}{*}{$\begin{array}{l}\text { Standard } \\
\text { deviation }\end{array}$} & \multirow[b]{2}{*}{$\mathrm{p}$-Value } \\
\hline & 1 & 2 & 3 & 4 & 5 & 6 & 7 & 8 & 9 & 10 & & & \\
\hline Before nebulization & 1748.4 & 1829.1 & 1950.6 & 1505.3 & 1624.4 & 1754.7 & 1411.7 & 1748.9 & 1696.1 & 1592.7 & 1686.18 & 157.6 & \\
\hline After nebulization & 1782.1 & 1823.9 & 1941.4 & 1495.2 & 1675.4 & 1680.3 & 1381.9 & 1681.4 & 1653.3 & 1469.5 & 1658.41 & 175.2 & 0.1249 \\
\hline
\end{tabular}

nebulizer is that the ultrasonic generator inputs highfrequency power to make high-frequency oscillation of the nebulizer film to atomize the solution into droplets with $1-5 \mu \mathrm{m}$ in diameter, which is close to the alveoli of lung in size. In addition, a normal ultrasonic nebulizer has its own air driving system, but after being connected to a ventilator, the air supply of the modified nebulizer will be replaced by the fresh air of the ventilator. Obviously, the driving power of the ventilator is stronger than the air driving system of the nebulizer. We surmise that the higher bioavailability of inhaled morphine in this study may be attributed to both the strong driving system of the ventilator and the matching size of the aerosol. Clinically, we can adjust the diameter of the aerosol, the inspiration velocity, and the inspiration time to facilitate the distribution of the drug to the alveoli of lung in the further study.

In the present study, that the dose of thev aerosol drug was twice that of the intravenous dose was established according to approximately $3 \mathrm{~mL}$ solutions remained unnebulized in this type of ultrasonic nebulizer. The residual liquor varies with different types of nebulizers; therefore, the dose of loaded drug should vary according to the type of the nebulizer.

In summary, our pharmacokinetic data shows that morphine administered by the ultrasonic nebulizer can be rapidly absorbed by the peripheral lung during mechanical ventilation, and has a better pharmacokinetics profile in slow release and lower toxicity than a typical bolus intravenous injection.

\section{Acknowledgments}

This research was funded by Nanjing Health Bureau.

\section{Author Disclosure Statement}

The authors declare that no conflicts of interest exist.

\section{References}

1. Thipphawong J, Babul N, Morishige R, Morishige RJ, Findlay HK, Reber KR, Millward GJ, and Otulana BA: An- algesic efficacy of inhaled morphine in patients after bunionectomy surgery. Anesthesiology. 2003;99: 693-700.

2. Fulda GJ, Giberson F, and Fagraeus L: A prospective randomized trial of nebulized morphine compared with patient-controlled analgesia morphine in the management of acute thoracic pain. J Trauma. 2005;59:383-388.

3. Slatkin N, Rauck R, Koczwara B, Chevlen E, Thipphawong J, Morishige R, Otulana B, Beckman R, and Gonda I: Analgesic efficacy of inhaled morphine delivered with the $\mathrm{AER}_{\mathrm{X}} \mathrm{TMmPMS}$ for breakthrough cancer pain. J Pain 2002; 3(Suppl.1):43.

4. Onal SA, Keleş E, Toprak GC, Demirel I, Alpay HC, and Avci L: Preliminary findings for preemptive analgesia with inhaled morphine: Efficacy in septoplasty and septorhinoplasty cases. Otolaryngol Head Neck Surg. 2006;135: 85-89.

5. Samir KB, Eugene RV, and Kenneth RE: Management of acute chest wall sickle cell pain with nebulized morphine. Am J Hematol. 2004;76:190-191.

6. Chrubasik J, Wüst H, Friedrich G, and Geller E: Absorption and bioavailability of nebulized morphine. Br J Anaesth. 1988;61:228-230.

7. Ward ME, Woodhouse A, Mather LE, Farr SJ, Okikawa JK, Lloyd P, Schuster JA, and Rubsamen RM: Morphine pharmacokinetics after pulmonary administration from a novel aerosol delivery system. Clin Pharmacol Ther. 1997;62: 596-609.

8. Masood AR, and Thomas SH: Systemic absorption of nebulized morphine compared with oral morphine in healthy subjects. Br J Clin Pharmacol. 1996;41:250-252.

9. Dershwitz M, Walsh JL, Morishige RJ, Connors PM, Rubsamen RM, Shafer SL, and Rosow CE: Pharmacokinetics and pharmacodynamics of inhaled versus intravenous morphine in healthy volunteers. Anesthesiology. 2000;93: 619-628.

10. Fok TF, Al-Essa M, Monkman S, Dolovich M, Girard L, Coates G, and Kirpalani H: Pulmonary deposition of salbutamol aerosol delivered by metered dose inhaler, jet nebulizer, and ultrasonic nebulizer in mechanically ventilated rabbits. Pediatr Res. 1997;42:721-727.

11. Köhler E, Sollich V, Schuster-Wonka R, and Hühnerbein J: Lung deposition in cystic fibrosis patients using an ultrasonic or a jet nebulizer. J Aerosol Med. 2003;16:37-46. 
12. Dhand R: Aerosol delivery during mechanical ventilation: from basic techniques to new devices. J Aerosol Med Pulm Drug Deliv. 2008;21:45-60.

13. MacLoughlin RJ, Higgins BD, Laffey JG, and O'Brien T: Optimized aerosol delivery to a mechanically ventilated rodent. J Aerosol Med Pulm Drug Deliv. 2009;22:323-332.

14. Khatri L, Taylor KM, Craig DQ, and Palin K: An assessment of jet and ultrasonic nebulisers for the delivery of lactate dehydrogenase solutions. Int J Pharmacol. 2001;227:121-131.

15. Xu X, and Wang X: Simulation analysis on nebulizing effects of supersonic atomizer adapted to ventilator. Inform Medical Equip. 2007;22:11-13.

16. $\mathrm{Xu} \mathrm{X}, \mathrm{Xu} \mathrm{J}$, and Wang $\mathrm{X}$ : Morphine nebulized by supersound atomizer for postoperative pain relieve in gynaecologic and obstetric patients. Chin J Postgrad Med. 2008, 31:21-24.
Received on December 16, 2010

in final form, October 11, 2011

Reviewed by:

Ronald Wolff

James Blanchard

Address correspondence to: Xiaohai Wang, M.D.

Anesthesiology Department

Nanjing Drum Tower Hospital

the Affiliated Hospital of Nanjing University Medical School

Zhong Shan Road 321

Nanjing, People's Republic of China 210008

E-mail: wxh32@jlonline.com 